\title{
Synthesis and properties of poly(butylene terephthalate)-b-polyisobutylene segmented block copolymers
}

\author{
E. Walch and R. J. Gaymans* \\ Twente University of Technology, Polymer Technology, PO Box 217, 7500 AE Enschede, \\ The Netherlands \\ (Received 18 June 1992; revised 24 May 1993)
}

\begin{abstract}
Segmented block copolymers of polyisobutylene (PIB) and poly(butylene terephthalate) (PBT) were made by condensation polymerization of $\alpha, \omega$-di-anhydride telechelic PIB, with 1,4-butanediol and dimethyl terephthalate. The inherent viscosity of the polymers was between 0.35 and $2.0 \mathrm{dl} \mathrm{g}^{-1}$. The extractability of the polymers with hexane was studied. The thermal behaviour of these polymers was studied by differential scanning calorimetry and dynamic mechanical thermal analysis. PBT-b-PIB had a glass transition temperature of $-62^{\circ} \mathrm{C}$ and a melting temperature of $200-220^{\circ} \mathrm{C}$. A shear modulus was found which, at room temperature, increased from 0.4 to $900 \mathrm{MPa}$ with increasing PBT content in the block copolymer. The degradation was followed by measuring the change of inherent viscosity during thermal and hydrolytic treatment. The PBT-b-PIB showed good resistance to thermal and hydrolytic degradation.
\end{abstract}

(Keywords: polyisobutylene; poly(butylene terephthalate); segmented block copolymer)

\section{INTRODUCTION}

Poly(butylene terephthalate) (PBT) has a high structural regularity, it crystallizes rapidly ${ }^{1}$ and has a high crystallinity. It has a melting temperature of $220^{\circ} \mathrm{C}$ and a heat of fusion of $52 \mathrm{~J} \mathrm{~g}^{-1}$. Because of its rapid crystallization, PBT is very suitable for use as the crystallizable segment in segmented block copolymers. Several PBT-based block copolymers have been studied in detail during the past 25 years $^{2-6}$.

Most commercial PBT-based block copolymers have a polyether (e.g. poly(tetramethylene oxide) (PTMO)) or aliphatic polyester amorphous phase. The use of aliphatic ether and ester amorphous blocks in copolymers has, however, some disadvantages. Polyethers are thermally unstable $^{7}$ and aliphatic polyesters have a low hydrolytic stability. It may be expected that employing olefinic amorphous blocks, such as polyisobutylene (PIB), ethylene-propylene rubber or dimerized fatty acids, will give more stable block copolymers. In the literature, there are only a few references to block copolymers with olefinic amorphous blocks'. One possible way to improve the hydrolytic and thermal stability is to use PIB as the amorphous phase. PIB is an amorphous polymer with a glass transition temperature, $T_{\mathrm{g}}$, of $-65^{\circ} \mathrm{C}$. It is chemically inert and thermally stable ${ }^{8,9}$. When stretched to high elongation, the polymer can crystallize in an orthorhombic crystal lattice ${ }^{10,11}$. The synthesis of PBT-b-PIB block copolymers with PIB blocks of $M_{\mathrm{n}}=5800$ has been reported $^{12,13}$. However, little information is given concerning the molecular weight and the homogeneity of the material.

* To whom correspondence should be addressed

0032-3861/94/030636-06

(C) 1994 Butterworth-Heinemann Ltd.
With dimerized fatty acids, thermoplastic elastomers with a high molecular weight can be polymerized ${ }^{14}$. If short blocks $\left(\mathrm{C}_{36}\right)$ are used, the glass transition temperature is relatively high for a thermoplastic elastomer. This can be improved by chain extension of the amorphous blocks with a short chain extender, or by using longer amorphous blocks ${ }^{15}$ (e.g. $\mathrm{C}_{72}$ diacids).

PBT and PBT block copolymers are polymerized in two steps ${ }^{7,16-18}$. The first step is a transesterification of dimethylterephthalate with a $10-50 \%$ excess of $1,4-$ butanediol at $180-220^{\circ} \mathrm{C}$ under atmospheric pressure. In the second step, the mixture is polymerized at $240-270^{\circ} \mathrm{C}$ under reduced pressure. Both steps are catalysed by weak acids, bases or metal salts ${ }^{19,20}$. Typically, titanium-based Lewis acids are used (e.g. titanium tetra-isopropoxide or titanium tetra-n-butoxide). According to the literature ${ }^{21}$, the titanate catalyst accelerates the reaction by a factor of $100-1000$.

The telechelic PIB used in this work is end-capped with maleic anhydride (MA) ${ }^{22,24}$. The anhydrides can react with alcohols to form an acid-ester. The reactivity of the remaining second acid of the anhydride is much less than that of the anhydride itself. From the literature ${ }^{23}$, it is also known that maleic acid gives mono-esters when the reaction is catalysed by $\mathrm{BF}_{3}$, whereas a plain acid-base reaction gives a mixture of mono- and di-esters. This indicates that the second acid group of maleic acid is not very reactive in esterifications catalysed by Lewis acids.

Our aim is to synthesize thermally stable block copolymers based on PIB-MA amorphous blocks and PBT crystallizable blocks (Figure l), and to study their properties as a function of the composition. 


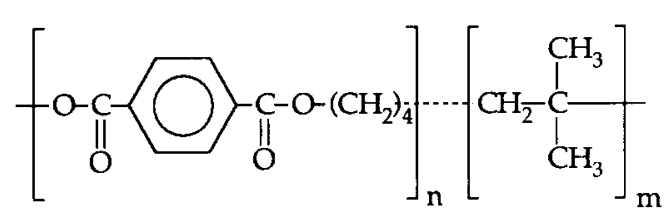

Figure 1 Schematic representation of PBT- $b$-PIB segmented block copolymer

\section{EXPERIMENTAL}

\section{Materials}

PIB telechelics with anhydride ends (PIB-MA) were synthesized as described previously ${ }^{24}$.

Dimethylterephthalate (DMT), 1-4-butanediol, titanium tetra-n-butoxide, $m$-cresol and hexane were from Merck and were used as received.

1,2,4-Trichlorobenzene was from Aldrich and was used as received.

\section{Synthesis}

The PBT- $b$-PIB synthesis was carried out in a stirred glass vessel that was immersed in an oil bath. For a 70/30 block copolymer, $7.5 \mathrm{~g}$ PIB-MA oligomer, $15 \mathrm{~g}$ DMT, $15 \mathrm{ml}$ 1,4-butanediol, $2 \mathrm{ml}$ catalyst solution ( $5 \mathrm{wt} \%$ titanium tetra-n-butoxide in 1,4-butanediol) and $35 \mathrm{ml}$ $m$-cresol were used. The reaction vessel was first flushed with nitrogen for $30 \mathrm{~min}$ and then the oil bath was heated to $200^{\circ} \mathrm{C}$ and stirring was started $\left( \pm 80 \mathrm{rev} \mathrm{min}^{-1}\right)$. After about $15 \mathrm{~min}$, methanol started to reflux. After a further 45 min of reaction, the pressure was gently reduced with a filter pump to $15 \mathrm{mmHg}$, while the temperature of the oil bath was raised to $250^{\circ} \mathrm{C}$. After $20 \mathrm{~min}$, most of the volatile components had been removed and the pressure was further lowered with an Edwards two-stage oil pump to $0.1-1 \mathrm{mmHg}$, while the temperature of the oil bath was raised to $260^{\circ} \mathrm{C}$. After $1 \mathrm{~h}$ reaction in vacuum, the reaction mixture was cooled to room temperature.

Some of the polymers were powdered and then post-condensed in the solid state in a stream of nitrogen at $180^{\circ} \mathrm{C}$ during $24 \mathrm{~h}$ at atmospheric pressure.

\section{Analyses}

Differential scanning calorimetry. Differential scanning calorimetry (d.s.c.) measurements were carried out with a Perkin-Elmer DSC-7. Heating and cooling rates were $20^{\circ} \mathrm{C} \mathrm{min}^{-1}$. The samples were heated to $20^{\circ} \mathrm{C}$ above the melting temperature and held in the melt for $5 \mathrm{~min}$ before being cooled. In a second run, they were melted again. The values from the second run were used as the melting temperature and the heat of fusion.

Dynamic mechanical thermal analysis. For the determination of the torsion modulus and the glass transition temperatures a Myrenne torsion pendulum (DSA, Germany) was used.

Block copolymer samples were melt-pressed at a temperature of $240-280^{\circ} \mathrm{C}$. The samples were 1.2 or $1.9 \mathrm{~mm}$ thick, $8-9 \mathrm{~mm}$ wide and $60 \mathrm{~mm}$ long. The torsion properties were measured with a heating rate of $\pm 1^{\circ} \mathrm{C} \mathrm{min}$ min $^{-1}$ at $2^{\circ} \mathrm{C}$ intervals. The torsion frequency was held at $1 \mathrm{~Hz}( \pm 12 \%)$.

Viscosimetry. The inherent viscosity of the polymers was determined with a $0.5 \%$ solution of the polymer in a mixture of phenol/1,1,2,2-tetrachloroethane (50/50 mole basis) at $25^{\circ} \mathrm{C}$. This solvent mixture is commonly used for pure $\mathrm{PBT}^{25}$ and proved also to be a suitable solvent mixture for the block copolymers ${ }^{12}$. Polymers were dissolved under stirring at $50^{\circ} \mathrm{C}$. Pure anhydrideterminated PIB oligomers did not dissolve in this mixture.

Degradation. Samples were melt-compressed and cut into small pieces, $2 \mathrm{~mm}$ thick. For thermal degradation the samples were placed in a stream of air at $150^{\circ} \mathrm{C}$ according to the ASTM D 865 norm. For hydrolytic degradation the samples were degraded in a damp atmosphere at $80^{\circ} \mathrm{C}$, according to the ASTM D 3137 method.

After different times, pieces were removed and dissolved in a phenol/tetrachloroethane mixture $(50 / 50 \mathrm{~mol} \%)$. The inherent viscosity of these solutions at $25^{\circ} \mathrm{C}$ was measured.

\section{RESULTS AND DISCUSSION}

\section{Polymerization}

Bulk polymerization. Some PBT- $b$-PIB block copolymers were synthesized in bulk without the use of solvents. The PIB-MA oligomers used had a molecular weight of 1500 . It was observed that, when stirring was stopped during the transesterification step, the PIB-MA floated to the surface of the reaction mixture, so the reaction mixture was not homogeneous in this first stage. It is likely that, in this case, only a suspension is present, with only a few chemical links between the reactive blocks. After the polymerization, the product was extracted with hexane. It was found that most of the PIB-MA could be extracted. This confirmed that in the case of synthesis without solvent, a mixture was obtained, and at the best only a small amount of block copolymer was formed.

Polymerization in a solvent. In order to homogenize the reaction mixture during the transesterification, a high boiling solvent was added. Good solvents in which the PBT as well as the PIB-MA could dissolve at $200^{\circ} \mathrm{C}$ were $m$-cresol and 1,2,4-trichlorobenzene. With both solvents, a clear solution was obtained at the synthesis temperature.

Nearly all polymers presented in this work were synthesized with $m$-cresol as a solvent. During the transesterification, a clear, homogeneous solution was obtained. The solvent was removed together with the surplus 1,4-butanediol by applying a vacuum during the polymerization at $260^{\circ} \mathrm{C}$. During this solvent removal, the polymer melt/solution became cloudy. It was not clear whether this was caused by a phase separation or the foaming of the polymer. (Polymer that crystallized under vacuum showed a large amount of $0.2-1.0 \mu \mathrm{m}$ holes when examined by scanning electron microscopy.)

\section{Inherent viscosity}

The synthesized polymers could be dissolved in a phenol/1,1,2,2-tetrachloroethane mixture and gave clear solutions within a day. With some post-condensed polymers, however, the solutions stayed hazy. This could be due to suspended PIB or PIB-rich particles, as PIB itself is not soluble in this solvent.

Although the clear solutions of the polymers could be filtered through glass filters, it was impossible to filter them through Millipore $(0.2 \mu \mathrm{m})$ filters. This indicates 
Table 1 Inherent viscosities, $\eta_{\mathrm{inh}}$, of the melt-polymerized polymers, transesterified in $m$-cresol

\begin{tabular}{lccll}
\hline Polymer & $M_{\mathbf{n}}(\mathrm{PIB})^{a}$ & $M_{\mathrm{n}}(\mathrm{PBT})^{b}$ & $\begin{array}{l}\text { PBT } \\
(\%)\end{array}$ & $\begin{array}{l}\eta_{\mathrm{inh}}{ }^{c} \\
\left(\mathrm{dl} \mathrm{g}^{-1}\right)\end{array}$ \\
\hline 1 & 600 & 600 & 50 & 1.77 \\
2 & 600 & 1400 & 70 & 2.01 \\
3 & 800 & 800 & 50 & 1.37 \\
4 & 800 & 1867 & 70 & 1.69 \\
5 & 900 & 900 & 50 & 1.77 \\
6 & 900 & 2100 & 70 & 1.77 \\
7 & 1500 & 808 & 35 & 0.50 \\
8 & 1500 & 1500 & 50 & 1.11 \\
9 & 1500 & 2786 & 65 & 1.27 \\
10 & 1500 & 6000 & 80 & 1.44 \\
11 & 1700 & 1700 & 50 & 1.26 \\
12 & 1800 & 1800 & 50 & 1.33 \\
13 & 1800 & 4200 & 70 & 1.43 \\
\hline
\end{tabular}

${ }^{a}$ Measured by osmometry

${ }^{b}$ Calculated from $M_{\mathrm{n}} \mathrm{PIB}$ and $\% \mathrm{PBT}$, assuming one carboxylic group of MA to have reacted

${ }^{c}$ In phenol/1,1,2,2-tetrachloroethane $(50 / 50 \mathrm{~mol} \%)$ at $25^{\circ} \mathrm{C}$

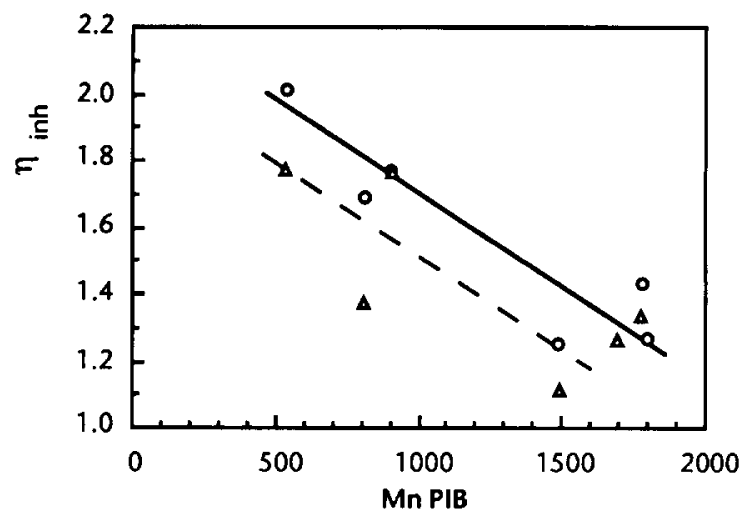

Figure 2 Inherent viscosity as a function of PIB block length for copolymers with $70 \mathrm{wt} \%$ PBT $(O)$ and $50 \mathrm{wt} \%$ PBT $(\triangle)$. Measured in phenol $/ 1,1,2,2$-tetrachloroethane at $25^{\circ} \mathrm{C}$

that microgels or very finely dispersed PIB aggregates or associates were present. As the solvent is a non-solvent for pure PIB, the block copolymer might phase-separate as micellar associates. For short PIB blocks and at the low concentrations that are used with viscosimetry, this should be a minor effect.

The results of some polymerizations are given in Table 1 . The inherent viscosities found are all very good. It is, however, possible that part of the anhydride ends have undergone difunctional reaction and in this way increased the inherent viscosity.

Figure 2 shows the viscosities from block copolymers with 50 and $70 \%$ PBT. It can be seen that the viscosity drops with increasing PIB block length when polymers with the same PBT weight fraction are compared. This drop is not caused by a poor functionality of the PIB oligomers, because this would give the opposite effect. Monofunctional PIB oligomers will decrease the molecular weight that can be achieved by the polycondensation reaction.

A likely reason for the observed viscosity change is not an effect of molecular mass but a change in the solubility with PIB block length, as pure PIB is insoluble in the solvent used. This could lead to a decrease of the hydrodynamic radius of the multiblock copolymers or even to associates. A lower inherent viscosity will result in these cases. This effect can also account for the lower inherent viscosity of the block copolymers with $50 \%$ PBT relative to those with $70 \% \mathrm{PBT}$.

\section{Extraction}

The presence of PIB homopolymer or PIB-rich fractions was studied by extracting the samples with hexane. PBT and the block copolymers are insoluble in hexane. PIB and block copolymer with very low PBT content are, however, soluble and are therefore extractable. The extraction was carried out in a Soxhlet apparatus for $16 \mathrm{~h}$. The presence of PBT homopolymer was not examined.

It was found that the amount of polymer extracted with hexane increases with increasing PIB content. If it is assumed that the extracted material is mainly PIB, the percentage of extracted PIB can be calculated. These values are given in Figure 3.

The extracted material was in all cases a sticky liquid that resembled the original PIB oligomer. Examination of the extract with i.r. spectroscopy showed that it contained some aromatic rings from the PBT. The PBT content of the extract is calculated by comparing the i.r. spectrum of a known composition (35\% PBT) with that of the extract. In this way it was calculated that the extract of sample no. 7 (35\% PBT) contained 17\% PBT. For this extracted polymer this means that there is about one aromatic ring for each PIB oligomer unit. It can be concluded that the extracted fraction still has a multiblock structure, but with very short PBT blocks.

The values of extracted PIB are rather high. Based on a random distribution of PIB in the PBT chain, the amount of these PIB-rich chains should not be so high. However, we saw the possible presence of meltphasing during synthesis, which was confirmed by optical microscopy. It is therefore possible that during the synthesis, the content of PBT in the phaseseparated PIB-rich material decreased further by means of transesterification reactions. This will also lead to an increase of the average PBT block length in the PBT-rich phase.

\section{Differential scanning calorimetry}

Melting temperatures. The thermal behaviour was studied with d.s.c. and the results are compiled in Table 2. The observed melting temperatures from the second heating run are given in Figure 4 as a function of the PBT block length. The figure also

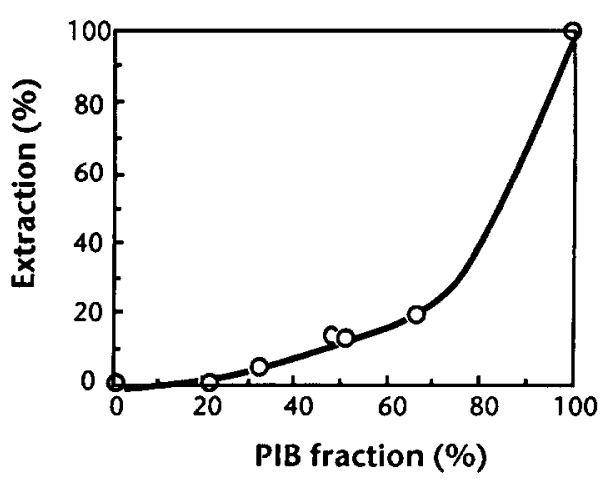

Figure 3 Hexane extracted mass as a function of the PIB fraction in the block copolymers after $16 \mathrm{~h}$ Soxhlet extraction $\left(M_{\mathrm{n}} \mathrm{PIB}=1500\right)$ 
Table 2 D.s.c. and torsion data of the PBT- $b$-PIB block copolymers

\begin{tabular}{|c|c|c|c|c|c|c|c|c|c|}
\hline Polymer & $M_{\mathrm{n}}(\mathrm{PIB})$ & $\begin{array}{l}\text { PBT } \\
(\%)\end{array}$ & $\begin{array}{l}T_{\mathfrak{m}} \\
\left({ }^{\circ} \mathrm{C}\right)\end{array}$ & $\begin{array}{l}\Delta H \\
\left(\mathrm{~J} \mathrm{~g} \mathrm{~g}^{-1}\right)\end{array}$ & $\begin{array}{l}\Delta H \\
\left(\mathrm{Jg} \mathrm{PBT}^{-1}\right)\end{array}$ & $\begin{array}{l}G^{\prime} 20^{\circ} \mathrm{C} \\
(\mathrm{MPa})\end{array}$ & $\begin{array}{l}G^{\prime} 100^{\circ} \mathrm{C} \\
(\mathrm{MPa})\end{array}$ & $\begin{array}{l}T_{\mathrm{g}}(\mathrm{PIB}) \\
\left({ }^{\circ} \mathrm{C}\right)\end{array}$ & $\begin{array}{l}T_{\mathrm{g}}(\mathrm{PBT}) \\
\left({ }^{\circ} \mathrm{C}\right)\end{array}$ \\
\hline PBT & - & 100 & 224 & 52.2 & 52.2 & 904 & 154 & - & 50 \\
\hline 10 & 1500 & 82 & 220 & 39.3 & 47.9 & 535 & 101 & -64 & 42 \\
\hline 14 & 2000 & 70 & 209 & 31.1 & 44.4 & 482 & 114 & -65 & 42 \\
\hline $14 \mathrm{P}^{a}$ & 2000 & 70 & 219 & 29.9 & 42.7 & 486 & 94 & -65 & 43 \\
\hline 15 & 3100 & 70 & 219 & 23.4 & 33.4 & 321 & 89 & -65 & 42 \\
\hline 9 & 1500 & 70 & 218 & 32.3 & 46.1 & 250 & 47 & -65 & 37 \\
\hline 6 & 900 & 70 & 216 & 26.4 & 37.7 & 462 & 89 & -68 & 46 \\
\hline 2 & 600 & 70 & 221 & 30.3 & 43.1 & 480 & 89 & -67 & 40 \\
\hline 13 & 1800 & 70 & 218 & 22.7 & 32.4 & 800 & 209 & -63 & 42 \\
\hline 4 & 800 & 70 & 218 & 25.7 & 36.7 & 463 & 80 & -60 & 41 \\
\hline $16^{b}$ & 800 & 70 & 211 & 37.8 & 54.0 & 290 & 63 & -64 & 41 \\
\hline 11 & 1700 & 50 & 207 & 17.6 & 35.2 & 57 & 7.5 & -63 & 29 \\
\hline 8 & 1500 & 54 & 213 & 19.3 & 35.7 & 8.0 & 1.3 & -65 & - \\
\hline $8 \mathrm{P}^{a}$ & 1500 & 54 & & & & 7.6 & 1.9 & -65 & - \\
\hline 5 & 900 & 50 & 207 & 13.7 & 27.4 & 95 & 15.5 & -63 & 42 \\
\hline 1 & 600 & 50 & 214 & 20.1 & 40.2 & & & -65 & 42 \\
\hline 12 & 1800 & 50 & 210 & 21.1 & 42.2 & & & & \\
\hline 3 & 800 & 50 & 209 & 23.6 & 47.2 & & & & \\
\hline 7 & 1500 & 35 & 196 & 7.3 & 20.9 & 2.6 & 1.1 & -65 & - \\
\hline $7 \mathrm{P}^{a}$ & 1500 & 35 & 196 & 3.1 & 8.9 & 1.1 & 0.3 & -65 & - \\
\hline PIB & - & 0 & - & 0 & - & 0.4 & - & -65 & - \\
\hline
\end{tabular}

${ }^{a} \mathbf{P}=$ post-condensed

${ }^{b}$ Synthesized in 1,2,4-trichlorobenzene as solvent

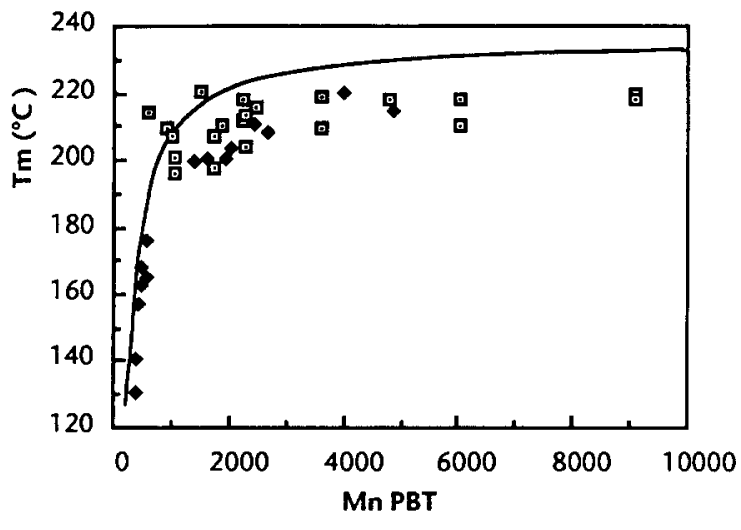

Figure 4 Melting temperature as a function of the calculated PBT block length. $\square$, PBT- $b$-PIB block copolymers; $\bullet$, PBT- $b$-PTMO from the literature ${ }^{30}$.

contains literature data of PBT- $b$-PTMO samples and a theoretical line, drawn according to Flory's theory for extended PBT chains ${ }^{26}$.

At molecular masses of 1000 and greater, we see that the PTMO-containing block copolymer has a lower melting temperature than that of a theoretically extended chain (Figure 4). This is caused by chain folding. In this case not the molecular length but the lamellar thickness should be used in Flory's calculations. At the side of low molecular weight blocks the points should, however, fall on the curve. The PBT- $b$-PTMO samples follow the theoretical line well for low molecular weights. Compared to the PBT- $b$-PTMO line, the melting points of PBT- $b$-PIB are slightly higher. This could be partly due to the incomplete incorporation of the PIB chains (Figure 3).
A second explanation for the difference in melting temperature between the PTMO and PIB block copolymers could be the solvation of the crystallites by the amorphous matrix. This effect is not often reported but is very noticeable with short crystallizable blocks ${ }^{27}$. It can be seen from the solubility parameters that PBT is less soluble in PIB than in $\mathrm{PTMO}^{8}\left(\delta_{\mathrm{PIB}} \approx 16.1\right.$, $\left.\delta_{\mathrm{PTMO}} \approx 17.1\left(\mathrm{~J} \mathrm{~m}^{-3}\right)^{1 / 2}\right)$. This means, in our case, that the melting point decrease of PBT crystallites due to the solvent effect will be smaller.

Crystallization rate. PBT homopolymer is a fast crystallizing polymer. By comparing the difference in melting and crystallization temperature (supercooling) with d.s.c. it is possible to examine the rate of crystallization in the block copolymers. As the crystallization rate is determined by nucleation and growth, it runs through a maximum with undercooling. At low temperatures, when the growth rate is decisive, the crystallization rate will be slower.

The melting temperatures and the crystallization temperatures were recorded with a constant heating or cooling rate of $20^{\circ} \mathrm{C} \mathrm{min}^{-1}$. The supercooling for all the block copolymers was found to be about $40^{\circ} \mathrm{C}$ over the whole range of $35-100 \%$ PBT. This supercooling is the same as for the PBT homopolymer. These results are in line with those observed for PBT- $b$-PTMO block copolymers $^{28}$. This means that the crystallization rate is independent of block length and composition in the examined range.

Glass transitions. With d.s.c., the glass transition of PIB was only seen in the pure homopolymer (Oppanol B50 from BASF). The PIB glass transition was too small 
to be seen in the block copolymers. The glass transition of PBT was only observed in samples with $70 \%$ or more PBT. Therefore d.s.c. was not used for determining the glass transitions.

\section{Dynamic mechanical thermal analysis}

Effect of composition on $\mathrm{G}$ modulus. The torsional moduli of some PBT- $b$-PIB block copolymers as a function of temperature are given in Figure 5. We see the presence of two glass transitions. This indicates that next to the crystalline phase, two amorphous phases are present.

The modulus of the PBT-b-PIB block copolymer decreased with decreasing content of crystallizable segments, but in a different way from that seen in the case of polymers with only one amorphous phase. With one amorphous phase a linear relation is found between $\log G^{\prime}$ and the fraction of crystalline material ${ }^{4}$. The modulus of PBT- $b$-PIB block copolymer dropped sharply around a 50/50 composition, as shown in Figure 6. This could be explained by a phase inversion around this composition, where the morphology of the amorphous phase changes from a PBT continuous phase to a PIB continuous phase. The modulus of a blend can be calculated with a Kerner relation. This relation is not fully valid for our case, but it can be used to estimate a minimum and maximum value for the modulus when

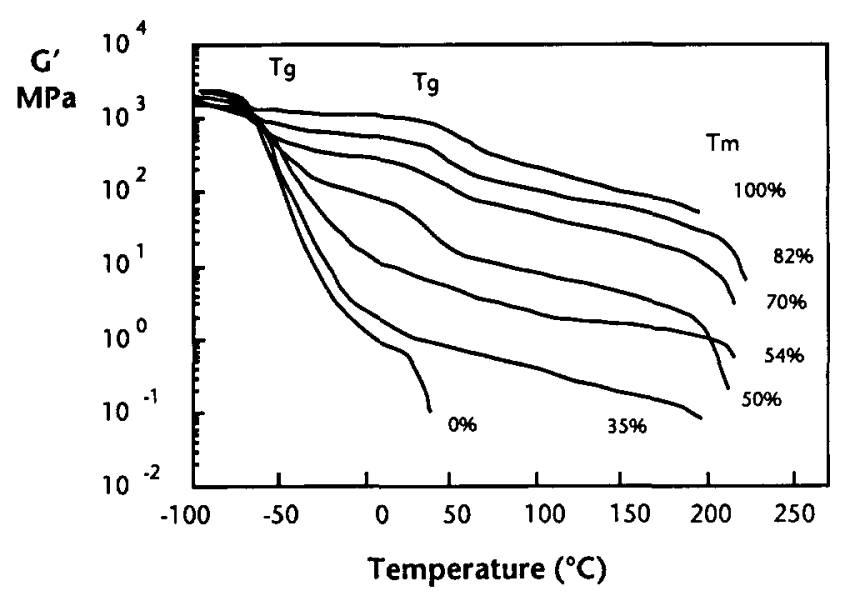

Figure 5 Torsional moduli of some PBT- $b$-PIB block copolymers with a PIB molecular weight of 1500 . The PBT content is given in wt $\%$ of the polymer. The $0 \%$ and $100 \%$ samples are high molecular weight homopolymers of PIB and PBT, respectively

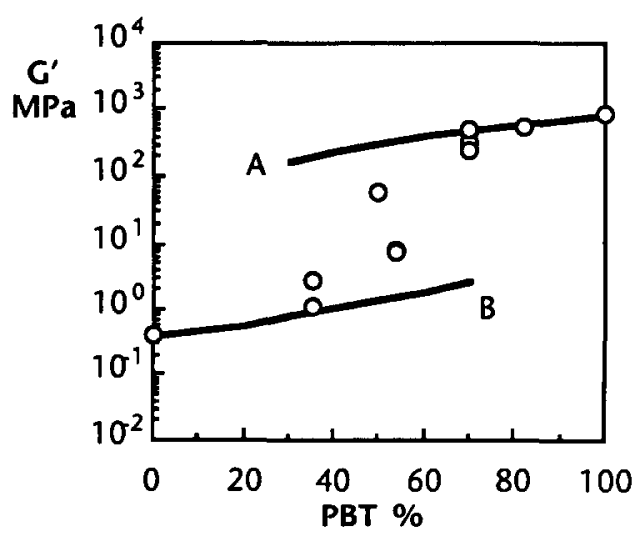

Figure 6 Measured torsion moduli at $20^{\circ} \mathrm{C}$ as a function of PBT content compared with $A$, inverse Kerner and $B$, Kerner relation

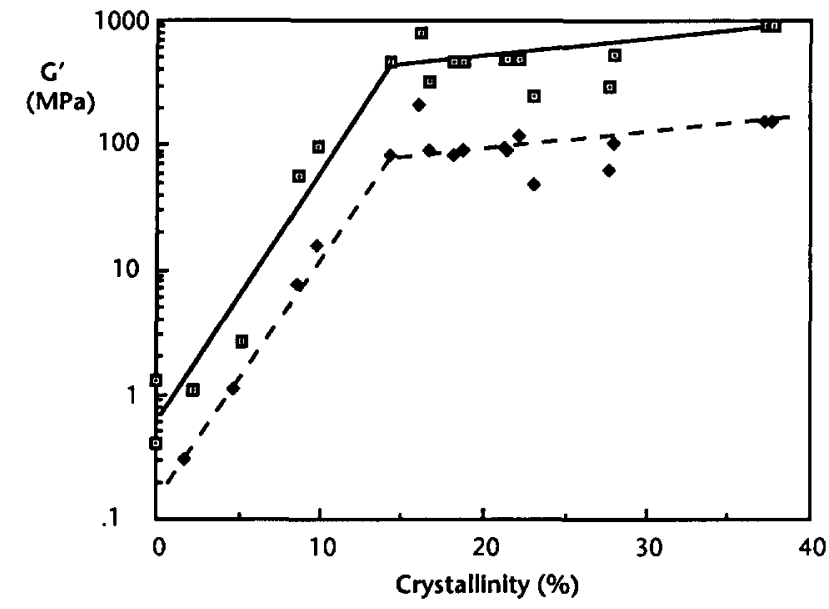

Figure 7 Torsion modulus $G^{\prime}$ as a function of the PBT crystallinity in PBT-b-PIB block copolymers at $20(\square)$ and $100^{\circ} \mathrm{C}(\bullet)$

one of the two phases is completely continuous. The results of these calculations are drawn in Figure 6 as the theoretical lines A and B.

The heat of fusion of PBT crystallites ${ }^{29}$ is $140 \mathrm{~J} \mathrm{~g}^{-1}$. The crystallinity of the block copolymers can be calculated with this value. Figure 7 shows the moduli as a function of the crystallinity. The moduli of PBT- $b$-PIB polymers do not show a linear relation with the crystalline fraction, as was found for the PBT- $b$-PTMO polymers ${ }^{4}$. The observed results can be divided into two regions, one with low and the other with high PBT content. In both regions a more or less linear relation is found.

The polymers with a low content of crystallizable segment had a rather low modulus for a block copolymer. This is because the PIB itself has a lower modulus $\left(G_{25^{\circ} \mathrm{C}}^{\prime} \approx 0.5 \mathrm{MPa}\right)$ than the amorphous polymers normally used, such as polyether or polyester $\left(G_{25^{\circ} \mathrm{C}}^{\prime} \approx 5 \mathrm{MPa}\right)$.

Effect of composition on PIB $\mathrm{T}_{g}$. The low temperature glass transition of the PIB phase was independent of the polymer composition (Table 2). In all cases, a $T_{\mathrm{g}}$ of about -62 to $-65^{\circ} \mathrm{C}$ was found. The $T_{\mathrm{g}}$ of a PIB homopolymer (Oppanol B50 from BASF) was found to be $-65^{\circ} \mathrm{C}$. This means that no, or almost no, PBT phase was dissolved in the PIB phase. This is valid even at the lowest PIB block lengths $\left(M_{\mathrm{n}} \approx 600\right)$.

Effect of composition on PBT $\mathrm{T}_{g}$. The $T_{\mathrm{g}}$ of PBT did not change much with composition, but the $T_{\mathrm{g}}$ was lower than in PBT homopolymer, and some samples with short PBT blocks showed a lower $T_{\mathrm{g}}$ than those with longer blocks (Table 2). It is not known whether this lowering is caused by a lowering of the block length or for another reason. It is suggested in the literature that the $T_{\mathrm{g}}$ of PBT is a function of its crystalline fraction. In non-crystalline PBT, one would find a $T_{8}$ of $15^{\circ} \mathrm{C}$ according to extrapolations made by Illers ${ }^{2 \rho^{g}}$.

\section{Degradation}

The stability against thermal degradation and hydrolytic degradation was followed by the change of inherent viscosity, $\eta_{\text {inh }}$. In Figure 8 the change of $\eta_{\text {inh }}$ is given as a function of the degradation time. To compare the different polymers, with different initial viscosities, all data were divided by the inherent viscosity at $t=0$. 


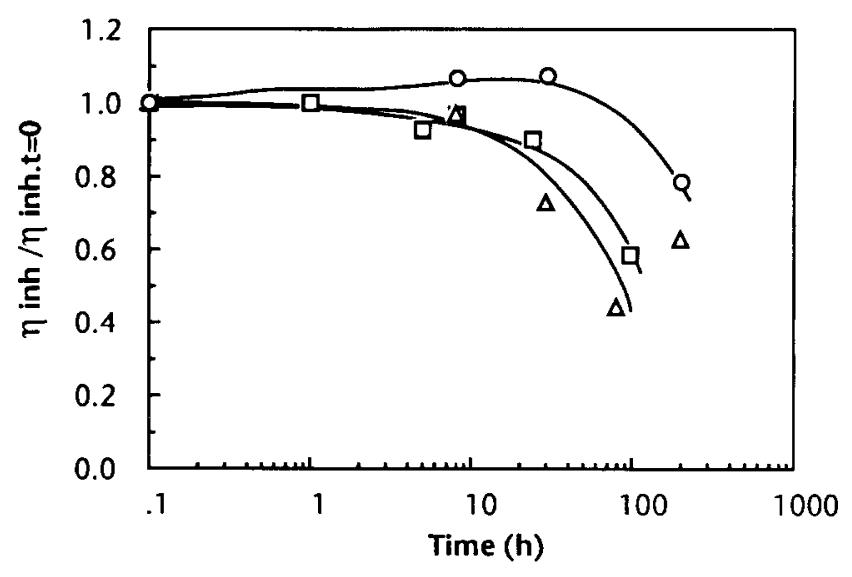

Figure 8 Measurement of inherent viscosity, $\eta_{\text {inb }}$, as a function of degradation time at $150^{\circ} \mathrm{C}$ in air: $\square, 82 \%$ PBT; $\triangle, 70 \%$ PBT; O, $54 \%$ PBT

The results show that the relative inherent viscosity drops only after heat treatment for $10 \mathrm{~h}$. This is considerably better than with unstabilized PTMO, which degrades within $1 \mathrm{~h}^{7}$. The results are comparable with those of very well stabilized PTMO $^{7}$.

The hydrolytic stability of the samples was examined by following the inherent viscosity of hydrolytically degraded samples. No degradation was observed up to $1000 \mathrm{~h}$.

\section{CONCLUSIONS}

PBT- $b$-PIB segmented block copolymers can be made by using $\alpha, \omega$-anhydride functionalized PIB, 1,4-butanediol and dimethylterephthalate. Because of a strong tendency for phase separation it is necessary to use a solvent, such as $m$-cresol or 1,2,4-trichlorobenzene, at the start of the reaction. Extraction with hexane showed that most of the PIB was incorporated in the segmented block copolymer. The obtained polymers were mainly linear, as they could be dissolved readily. This means that the reaction of the anhydride end-groups was mainly monofunctional. To obtain more conclusive results, some model compounds with only one anhydride end should be made and characterized.

The block copolymers synthesized from PIB and PBT showed thermoplastic elastomeric properties. All polymers had a low glass transition temperature of about $-65^{\circ} \mathrm{C}$, which is much lower than that of normal, commercial thermoplastic elastomers synthesized from aliphatic esters or polyethers. The change of the elastomer to PIB led to an increased thermal stability, and permitted the synthesis of thermoplastic elastomers with a lower modulus than was possible with the esters or ethers.

\section{ACKNOWLEDGEMENT}

This work is part of the research programme of the University of Twente and was financially supported by the Netherlands Innovative Research Programme for Polymers (IOP).

\section{REFERENCES}

Pratt, C. F. and Hobbs, S. Y. Polymer 1976, 17, 12

Cella, R. J. J. Polym. Sci., Polym. Symp. 1973, 42, 727

Seymour, R. W., Overton, J. R. and Corley, L. S. Macromolecules $1975,8,331$

4 Zhu, L., Wegner, G. and Bandara, U. Makromol. Chem. 1981, 182, 3639

5 Schroeder, H. and Cella, R. J. 'Encyclopedia of Polymer Science and Technology' (Eds H. F. Mark, N. M. Bikales, C. C. Overberger and G. Menges), Vol. 12, 2nd Edn, Wiley, New York, p. 75

6 Bandara, U. and Dröscher, M. Colloid Polym. Sci. 1983, 261, 26

7 Hoeschele, G. K. Angew. Makromol. Chem. 1977, 58/59, 299

8 van Krevelen, D. W. 'Properties of Polymers' 3rd Edn, Elsevier, Amsterdam, 1990, p. 642

9 Mita, I. in 'Aspects of Degradation and Stability of Polymers', Elsevier, Amsterdam, 1978

10 Tanaka, T., Chatani, Y. and Tadokoro, H. J. Polym. Sci., Polym. Phys. Edn 1974, 12, 515

11 Iannelli, P. and Immirzi, A. Macromolecules 1989, 22, 200

12 Peters, E. N. (GEP), European Patent Application 88111664.4 , 1989

Peters, E. N. (GEP), US Patent 4845158,1989

Manuel, H. J. and Gaymans, R. J. Polymer 1993, 34, 636

Manuel, H. J. and Gaymans, R. J. Polymer in press

Wilfang, R. E. J. Polym. Sci. 1961, 54, 385

Wolfe, J. R. in 'Block Copolymers, Science and Technology', Symposium Series, Harwood Academic, London, 1979

18 Goodman, I. 'Encyclopedia of Polymer Science and Technology' (Eds H. F. Mark, N. M. Bikales, C. C. Overberger and G. Menges), Vol. 12, 2nd Edn, Wiley, New York, p. 1

19 Tomita, K. and Ida, H. Polymer 1975, 16, 185

20 Tomita, K. Polymer 1976, 17, 221

21 Laurienzo, P., Malinconico, M., Martuscelli, E. and Volpe, M. G. Polymer 1989, 30, 835

22 Walch, E. and Gaymans, R. J. Polymer 1993, 34, 412

23 Nieuwland, J. A., Vogt, R. R. and Foohey, W. L. J. Am. Chem. Soc. 1930, 52, 1018

24 Walch, E. and Gaymans, R. J. Polymer in press

25 Borman, F. H. J. Appl. Polym. Sci. 1978, 22, 2119

26 Mandelkern, L., Garret, R. R. and Flory, P. J. J. Am. Chem. Soc. 1952, 74, 3949

27 van Hutten, P., Magnus, R. and Gaymans, R. J. Polymer in press

28 Hoeschele, G. K. and Witsiepe, W. K. Angew. Makromol. Chem. $1973,29 / 30,267$

29 Illers, K. H. Colloid Polym. Sci. 1980, 258, 11

30 Wegner, G. in 'Thermoplastic Elastomers', Hanser, Munich, 1987, Ch. 12, Sect. 5 